\title{
Literatura digital para crianças: textos, leitores e práticas educativas
}

\author{
Digital Literature for Children: Texts, Readers and Educational \\ Practices
}

https://doi.org/10.34112/2317-0972a2016v34n68p169-173

EDgar RobERTO KiRCHOF ${ }^{1}$

Rosa Maria Hessel Silveira

MANRESA, Mireia; REAL, Neus. Digital Literature for Children: Texts, Readers and Educational Practices. Brussels: Peter Lang, 2015.

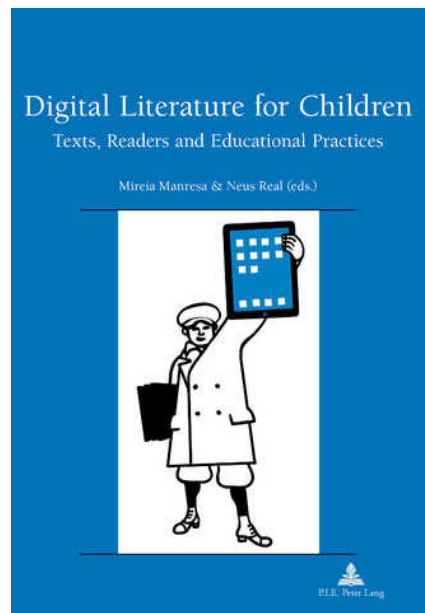

1. Professor vinculado ao Programa de Pós-graduação em Educação da Universidade Luterana do Brasil, Canoas, RS, Brasil.E-mail: ekirchof@hotmail.com.

2. Professora vinculada ao Programa de Pós-Graduação em Educação da Universidade Federal do Rio Grande do Sul, Porto Alegre, RS, Brasil.E-mail: rosamhs@gmail.com. 
Digital Literature for Children: Texts, Readers and Educational Practices, organizado pelas pesquisadoras da Universidade Autônoma de Barcelona Mireia Manresa e Neus Real e publicado pela editora P.I.E. PETER LANG, em 2015, é obra que resultou de palestras proferidas no evento $L a$ Literatura en pantalla: textos, lectores y prácticas docentes, ocorrido em Barcelona em 2014, em promoção do Grupo de Investigación en literatura infantil y juvenil y educación literaria (GRETEL), sob coordenação da conhecida pesquisadora catalã Teresa Colomer.

Além de convidados renomados, como a pesquisadora nipo-norte-americana Yunko Jokota, pesquisadora sobre livros digitais infantis, e Kate Pullinger, escritora canadense pioneira no campo, várias palestras trouxeram resultados do projeto $R \& D$ Literatura infantil y juvenil digital: producción, usos, lectores, recepción y prácticas docentes, realizado no GRETEL.

Embora constituído por pesquisas e reflexões enraizadas no contexto social, econômico e cultural de países europeus e norte-americanos, o livro traz contribuições valiosíssimas para professores, artistas, editores e pesquisadores brasileiros interessados no modo como leitores jovens e infantis se relacionam com as novas formas literárias que vêm surgindo, nos últimos anos, devido à evolução das mídias produzidas com tecnologia digital.

O livro está estruturado em 5 seções, sendo a primeira - Contextualização $e$ pano de fundo teórico ${ }^{3}$ - integrada por dois artigos: O leitor (no) digital, formas de leitura na tela, de Laura Borràs, e Lugares comuns na literatura eletrônica para crianças. Uma jornada através dos espaços definidores da literatura eletrônica, de Lucas Ramada Prieto. No primeiro, Borràs explora as possibilidades da leitura (no) digital a partir de "diferentes modos de ler nas telas, através das telas" (p. 27), mapeando conceitos frequentes nas discussões do tema, como ecossistema de leitura, prosumption (neologismo que combina as palavras produtor e consumidor para definir o leitor digital), leitura expansiva, booktubers, leitura transmídia etc. No segundo, além de definir as principais características da literatura eletrônica para crianças/adolescentes, o autor também explora questões de estética digital.

Na segunda seção, Literatura digital para crianças e adolescentes, os três artigos, juntos, fornecem um excelente estado da arte sobre o tema. Em $O$ impacto dos novos meios digitais sobre a literatura infanto-juvenil, a autora alemã Bettina

3. Todas as traduções são da responsabilidade dos resenhistas. 
Kümmerling-Meibauer, entre outros tópicos, discute o crescente fenômeno fan fiction, que vem transformando as relações entre autores e leitores no universo digital. Já em $O$ passado, o presente e o futuro dos livros digitais de imagem para crianças, Junko Yokota discute os tipos de conteúdo para crianças que seriam adaptáveis para o formato digital, propondo uma ordem de progressão de tipos de obras para tal adaptação: obras de referência, obras informativas, capítulos de livros/romances, livros narrativos de imagem. Por fim, no artigo Literatura eletrônica para crianças: caracterizando aplicativos narrativos (2010-2014), Celia Turrión Penelas fornece um modelo de análise de aplicativos narrativos para crianças, criado a partir do estudo de um conjunto de obras desenvolvidas desde 2010 (quando surgiu o iPad).

A terceira seção, Leitores e literatura digital, abrange três artigos resultantes da pesquisa realizada pelo GRETEL (já citada). Em Leitores tradicionais e literatura eletrônica. Uma exploração de percepções e leituras de obras digitais, Mireia Manresa expõe os resultados de uma prática de leitura de cinco obras, analisando se e como crianças/adolescentes incorporam elementos digitais ao interpretarem as narrativas. Já no artigo Migrações digitais: pesquisa exploratória dos perfis de leitura de literatura eletrônica para crianças, Lucas Ramada Prieto e Lara Reyes López trazem resultados de um experimento com leitura de 16 obras literárias digitais baixadas em tablets, traçando diferenças entre perfis de leitores de obras impressas e de obras digitais. Em Papel ou digital: uma leitura comparada de um conto de Poe com adolescentes, Martina Fittipaldi, Anna Juan e Mireia Manresa analisam as discussões literárias feitas por dois grupos de leitores infantojuvenis que leram o conto Tell Tale Heart, de Edgar Allan Poe, ou em suporte impresso ou em adaptação digital. Entre outras conclusões, as autoras observaram que, "enquanto os leitores da versão digital tinham que concentrar sua atenção apenas nas palavras, os leitores do aplicativo precisaram enfrentar uma grande quantidade de estímulos multimodais que podem tê-los distraído do texto impresso e direcionado sua atenção para outros componentes" (p. 143).

Na quarta seção, Práticas educativas: famílias e escolas, três artigos focalizam práticas de leitura e letramento literário nestes contextos. Em iPads, leitores emergentes e familias, Cristina Aliagas e Ana M. Margallo refletem sobre transformações advindas da "prática da leitura compartilhada entre adulto e criança e a proeminência que o tablet adquiriu com a implantação da literatura eletrônica para crianças” (p. 156). Já em Literatura digital na primeira infância. Experiências de leitura na familia 
e em contextos escolares, Neus Real e Cristina Correro se detêm na comparação de dois contextos diferentes: a escola (educação infantil) e o espaço familiar, com base em observações neles feitas. No último artigo da seção, Lendo literatura na tela em uma biblioteca escolar, Teresa Colomer e Karla Fernández de Gamba Vázquez trazem resultados de investigação realizada na biblioteca de uma escola, sendo que uma das principais conclusões é que a leitura de fiç̧ão em formatos digitais não prejudica o interesse dos alunos por obras impressas, desde que eles já possuam previamente um bom nível de leitura literária.

A última seção do livro, Criando textos digitais: duas reflexões, é composta por dois artigos cujos autores têm um perfil distinto dos demais, como artistas envolvidos na criação de obras para crianças/ adolescentes: Kate Pullinger, uma das criadoras de Inanimate Alice, e o ilustrador catalão Arnal Ballester. Em Inanimate Alice - como nós incidentalmente criamos uma história digital para as escolas, Pullinger aborda o inusitado processo que levou a obra a se tornar uma narrativa digital extremamente popular em escolas de diferentes países, já que, originalmente, ela havia sido concebida como uma peça de publicidade para promover um filme ainda em produção. Em Mudança de direção, Arnal Ballester reflete sobre algumas das transformações desencadeadas no processo da leitura e da produção dos livros a partir do surgimento dos aparelhos eletrônicos.

Cabe ressaltar que, no Brasil, o acesso à Internet e a popularização de aparelhos como smartphones, iPads e outros dispositivos móveis não são tão generalizados como em países ricos, o que tem limitado, por enquanto, a produção de livros em formato de aplicativos. Assim, a produção de literatura digital no país é ainda relativamente limitada, em comparação com o que ocorre em países europeus e nos Estados Unidos, apesar dos esforços de artistas pioneiros como Ana Cláudia Gruszynski e Sérgio Caparelli, Angela Lago, Alckmar dos Santos, Gilberto Prado, os irmãos Campos, entre outros, e também dos esforços empreendidos pelo mercado editorial. Nesse contexto, merece um destaque especial a inclusão da categoria "Jabuti digital", desde 2015, no mais tradicional prêmio do livro no Brasil, o Jabuti, que existe desde 1958.

Entretanto, mesmo que de forma mais lenta que em países ricos e apesar das particularidades que assume, também no Brasil a literatura digital vem sendo produzida, consumida e pesquisada pelo menos desde a década de 1990; o endereçamento específico para adolescentes e crianças tem se intensificado a partir de 2010, com o surgimento do iPad. Assim sendo, a despeito de tais diferenças, a obra 
Digital Literature for Children: Texts, Readers and Educational Practices traz questionamentos, provocações e muitas informações atualizadas para as pesquisas realizadas entre nós sobre leitura e produção de obras digitais, servindo não apenas como inspiração para investigações futuras, mas também apontando caminhos teóricos e metodológicos possíveis e desejáveis.

Recebido em o8 de julho de 2016 e aprovado em 15 de dezembro de 2016. 